\title{
Rulfo Sin Orillas
}

A Rulfo lo llamamos épico, trágico. Nos sigue impresionando su lirismo austero. Pero hay otro plano, otro tono más crepuscular. Es el ambiente del sueño ontológico del hombre devorado por la materia.

La materialidad, en Rulfo, ${ }^{*}$ invade, absorbe al hombre, lo disuelve en imágenes. A1 contacto con la materia se produce una especie de combustión. Del polvo de los huesos brota luz; de la boca llena de tierra, una lengua de fuego. La cifra de esta "combustión" " es Pedro Páramo: roca y desierto; pero desierto vibrante de ecos y reflejos. Se

*Cito por Pedro Paramo (México: Fondo de Cultura Económica, Colección Popular, 1969). Para El llano en llamas, edición de 1965, también del F.C.E., salvo "La herencia de Matilde Arcángel"' y "El día del derrumbe", que cito por la edición de 1973.

I Materia que devora:

el viento negro de "Luvina"' (pp. 94-95);

la gotera que taladra a Pedro Páramo cuando piensa en Susana (p. 15)

el polvo en "Talpa" (p. 60)

la tierra en "La noche que lo dejaron solo" (p. 106)

Una pequeña "combustión" en "La Cuesta de las Comadres"': el asesinato de Remigio Torrico, "a la altura de las fiestas de Zapotlán" , se volatiliza-vuelos de zopilotes, estallidos de cohetes-en el horizonte del recuerdo (p. 30).

Asi también, la agonia de Tanilo en "Talpa" se acompaña de fogatas (p. 62), esqueléticas danzas de sonajas' y llamaradas de velas (p. 63).

Fantasmagóricas luces de linternas que apuntan desde "el otro lado" en el momento de la muerte, en "Paso del Norte" (pp. 124-125).

Sustancia onírica: la llovizna que crece, se vuelve lágrimas (p. 19), "cántaro raso" de dolor en el que se refleja todo el "peso del sueño (pp. 27-28) que anuncia la muerte del padre de Pedro Páramo.

La "época del aire": : una de las pequeñas magias de Rulfo. Epoca, a la vez, del ano-primavera, viento que hace volar los papalotes-y de la vida. Epoca, también, de la ilusión que, como el hilo del papalote, corre entre los dedos (p. 16). Símbolo que se enriquece con la muerte de Susana que, como el "pájaro de papel" (p. 16) pasa rozando las ramas del paraíso (el árbol de la felicidad) al alejarsé "entre las sombras de la tierra" (p. 122).

Ladrando, el horizonte se acerca. En "Nos han dado la tierra " (p. 15): "Uno ha creido a veces...que no se podría encontrar nada al otro lado, al final de esta llanural rajada de grietas y de arroyos secos. Pero si, hay algo. Hay un pueblo. Se oye que ladran los perros"; y al rato: "el pueblo está todavía muy allá. Es el viento el que lo acerca". La imagen se invierte, el horizonte se aleja en "Luvina": "Un lugar moribundo donde se han muerto hasta los perros y ya no hay ni quien le ladre al silencio'" (p. 104). 
podría decir que al consumirse el hombre se volatiliza. Hay algo sin orillas: una sustancia onírica multiplicándose en la conciencia que se proyecta en imposibles cielos, paraísos; como la famosa "época del aire" de Pedro Páramo: fantasia, desde la ultratumba, de infancia, amor, felicidad. Del fondo del sueño nace el mito: el horizonte perdido.

Ladrando, a veces, el horizonte se acerca. 'Pienso en esos perros infernales que, a través de sus misteriosas transformaciones, animan de falsa esperanza al que vaga en el oscuro resplandor de la noche.

Son los ladridos lunares de "No oyes ladrar los perros". Bostezos del espacio, del vacío que se abre, radiante y nocturno. Como tantas veces en Rulfo: un padre, un hijo que se martirizan, entretejen sus sombras agónicas. En primer plano, la luna: "llamarada redonda" "2 que los encandila. Han hecho camino, a ciegas, "pasado el cerro". La frase no deja de hacerse notar. Es un cerro cargado de sentido: una frontera. Del otro lado llaman

2 La luna, "llamarada redonda" (p. 114): es la luz del sueño que ilena los ojos, se refleja, opaca, en la cara del moribundo (p. 115).

El cerro, una frontera: es el paso al más allá, al otro mundo. El padre ya lo sabe: "Este no es ningún camino" ( $p$. 115). Otra forma de decirlo: "detrasito del monte" (p. 114). Ecos del "monte que no dejaba volver a nadie" de "La Cuesta de las Comadres", (p. 22).

Los perros de la muerte: "Alli estaba el pueblo. Vio brillar los tejados bajo la luz de la luna. Tuvo la impresión de que lo aplastaba el peso de su hijo..." "Destrabó difícilmente los dedos con que se hijo habia venido sosteniéndose de su cuello y, al quedar libre, oyó cómo por todas partes ladraban los perros" (p. 118).

Laboriosa pendiente, cansancio que se corporiza : "El sueño le nublaba el pensamiento". "Ahora, en la subida, lo vio venir de nuevo. Hasta que lo tuvo encima..." " "..trepado alli donde su espalda se encorvaba" (p. 105). El peso del sueño recuerda el del hijo moribundo de "No oyes ladrar los perros".

"Tiempo tibio", llanura soleada: "Allá abajo el tiempo tibio", (p. 106); "allá lejos la gran llanura gris" donde los compañeros deben estar "descansando al sol" ' (p. 107). Curioso ese sol de la llanura gris; hay que pensar en el sol crepuscular del suefio que, efectivamente-y casi sin transcurrir el tiempo-se disuelve en la "lumbre" nocturna de las "grandes fogatas"' (p. 108).

Otro cerro-frontera con vista a la llanura: el Cerro Grande de "E1 llano en llamas", desde donde "pasábamos el tiempo mirando hacia el Llano, hacia aquella tierra de allá abajo donde habíamos nacido y vivido y donde ahora nos estaban aguardando para matarnos"' (p. 82).

“"Encumbrar", la sierra (p. 107); "Y se dejó caer barranca abajo, rodando y corriendo y volviendo a rodar"' (p. 107).

"Ahora el sueño lo hacía hablar"' (p. 106); "Se detuvo con.los ojos cerrados"' (p. 106); "Y casi en secreto" (p. 106).

El paso a la muerte dentro del sueno: al recostarse el hombre en un tronco (entregarse al suefio), lo absorben " 1 a tierra fría", el musgo (p. 106). Las demás citas son de la misma página.

El amanecer invertido en sensación de anochecer refleja lả inversión del sol en fogata nocturna (pp. 107-108).

Otro amanecer-en este caso de "luz parda" y "cielo plomizo" - que anuncia "el principio de la noche", en Pedro Paramo (p. 28).

El tronco, símbolo de sueño y de muerte: ver "La Cuesta de las Comadres" (p. 25), "Es que somos muy pobres"' (p. 33), "Luvina"' (p. 104), "El llano en llamas"' (p. 67).

"El dia del derrumbe"' (p. 134); "En la madrugada"' (p. 51).

La misma duda: ver "La Cuesta de las Comadres", (p. 25).

Los Torricos, señores del submundo: también Pedro Páramo es el señor del sueño, de la noche, que domina todo el espacio "terrenal" desde la Media Luna (p. 10). Y don Justo- "En la madrugada"-es "dueño de la luz" (p. 53).

El "reparto", de la reforma agraria (p. 21); "dueños de la tierra" (p. 21). 
los perros. Parece que anuncian la vida: el pueblo de tejados brillantes. Pero lloran la muerte del que llega.

Hay otro cerro-frontera en "La noche que lo dejaron solo"'. Laboriosa pendiente donde un fugitivo se rezaga, se duerme. El cansancio se corporiza en el paisaje lento, sonámbulo. Lo que el hombre carga, esta vez, es su propio peso, "trepado", en la espalda. "Allá lejos", como siempre, está "el tiempo tibio" de la llanura soleada. Para llegar hay que "encumbrar" la sierra, después dejarse caer, interminablemente, "barranca abajo, rodando". La huida es real, pero al ritmo del sueño: el tiempo suspendido del que mira "con los ojos cerrados", se habla "casi en secreto", para adentro, balanceando la cabeza. El paso a la muerte, dentro del sueño, es leve. Basta abrir los brazos como para "medir el tamaño de la noche", darse contra "una cerca de árboles". Pero el sueño sigue, enredado en las ramas; en el "aire oloroso" del tronco tutelar. Por eso, amaneciendo, el hombre siente que oscurece. Lo duerme el cielo claro de estrellas transparentes. Y lo despierta el humo de las fogatas que nubla los ojos de sus compañeros muertos.

En " $E 1$ día del derrumbe" un hombre no recuerda ni dónde ni cuándo lo " agarró" el temblor. Y también el preso de "En la madrugada" se pregunta cómo puede haber matado a un hombre sin darse cuenta.

La misma duda en "La Cuesta de las Comadres", donde reinan esos señores del submundo, los Torricos. Cuando el "reparto" de la reforma agraria, los Torricos, rel'egados al monte, quedaron sin embargo "dueños de la tierra". Desde las sombras se proyectan-y a ratos se materializan-en la imaginación de la gente. Casas, maizales, "lomas verdes" "3" les pertenecen en su palpitante destierro. La Cuesta, se podría decir, es el sueño de los “difuntos Torricos"'. En su fuego espectral la gente se consume, se borra. La Cuesta se va deshabitando. La muerte-espejismo flotante-llama " atrás del monte que no dejaba volver a nadie"'.

Queda el Guardián-otro soñador-sentado en la Cuesta, recordando. Es el irónico buen amigo de los Torricos, cuya guadaña fue una aguja de arria en la luz de la luna. Lo podemos ver esperando a Remigio Torrico, tejiendo, bordando su mortaja: "remendando mi costal'".

Sabemos de Remigio que a su modo, como tantas almas sufrientes de Rulfo, era visionario: un tuerto con el otro ojo-el bueno, "negro y medio cerrado" que "parecía

\footnotetext{
3: "lomas verdes"' (p. 21); los “difuntos Torricos"' (p. 21); la Cuesta se va deshabitando (p. 21); " atrás del monte que no dejaba volver a nadie" (p. 22).

El Guardián de los muertos: ver "les cuidé sus casas" etc. (p. 22). Sentado en la cuesta (p. 23); la "agu ja de arria"' (p. 27); 'remendando mi costal"' (p. 27).

Los ojos de Remigio Torrico (p. 23).

"Entonces me di cuenta que me faltaba algo. Como que la vida que yo tenia estaba muy desperdiciada y no aguantaba más estirones"' (p. 24). El "estirón" , claro, es él suefio. Ver el paisano que "estira los ojos" hacia el cielo en "Nos han dado la tierra"' (p. 15).

Muerte del arriero (p. 25). Notar mismo ambiente lunar en el asesinato de Remigio: "Me acuerdo que había una luna muy grande y muy llena de luz"' (p. 26); "la aguja de arria trabajaba muy bien cuando la alumbraba la luz de la luna" (p. 27).

"Me acuerdo" (pp. 23 y 30). Misma obsesión reiterativa -otra fórmula-en “Acuérdate"' (pp. 110-113).
} 
acercar tanto las cosas" - puesto en el horizonte. Y su misterioso " alcance de vista"' sigue en la muerte. Es el párpado de la pesadilla en el ojo de la tierra.

Los soñadores, podríamos decir, no son más que momentos en el flujo de la materia que sueña. Al Guardián, en época de los Torricos, sólo le falta " algo", un "estirón" para identificarse con ellos. Los acompaña, los observa una noche en que matan a un arriero. Es una muerte de sueño en un ambiente lunar. El arma, también de sueño, es un leño en manos de Odilón Torrico. El arriero anda y de pronto se está quieto; "cansado de esperar", se duerme. "Tantito atarantado", dice un Torrico, aunque ya suena a "tronco seco". Todo ocurre como más allá de los hechos, con gestos sordos. Una supuración momentánea del paisaje, en que el reiterativo "me acuerdo" es parte del olvido.

La tierra-madre y tumba-traga y devuelve: es "La herencia de Matilde 'Arcángel'’.

A Matilde, como la Susana ${ }^{4}$ de Pedro Páramo, la sabemos de otro mundo remoto, florido. Un mundo de felicidad o de locura, pero siempre de plenitud inaccesible: el mundo del ser. La ilusión lo coloca "arriba" o, para los arrieros, "caído en el crepúsculo...donde se nos acababa la jornada". De allí brota Matilde con su "mirada de semisueño": ánima que se encarna. Otra musa raptada por las olas; la boca reventada "como si se la hubieran desflorado a besos". Y, por un momento, se deja penetrar "más

\footnotetext{
4 'Susana: "Una mujer que no era de este mundo" (p. 113).
}

Un lugar "más arriba" (p. 144); "caído en el crepúsculo" (p. 145); “mirada de semisueño" (p. 145); reventada la boca (p. 145).

Musa raptada por las olas: Susana (p. 100).

"Y más que trabajando, se había metido dentro de ella mucho más allá de las orillas de la carne, hasta el alcance de hacerle nacer un hijo"' (p. 146).

El soplo del caballo: "Pasó junto a nosotros como una nube gris, y más que caballo fue el aire del-caballo el que nos tocó ver"' (p. 146). "Por eso es que todavia siento pasar junto a mí ese aire, que apagó la llamarada de su vida, como si estuviera soplando; como si siguiera sopl indo contra uno"' (p. 147). En Pedro Páramo, otro caballo de sueño: el que anuncia la muerte de Miguel (pp. 25-26).

"Aliento" y flauta del hijo de Matilde (pp. 148-149).

Caballos apocalipticos que vuelven (pp. 149-150). Jinetes flacos y dormidos (p. 150).

“Angustia" de Matilde (p. 147); la fosa y el "charco lodoso" (p. 147). "La Matilde Arcángel se había quedado atrás, sembrada no muy lejos de allí y con la cara metida en un charco de agua" (p. 146).

La muerte de la tía Jacinta (p. 31).

El río es el sueño que crece: "El río comenzó a crecer hace tres noches, a eso de la madrugada. Yo estaba muy dormido y, sin embargo, el estruendo que traía el río al arrastrarme me hizo despertar en seguida y pegar el brinco de la cama con mi cobija en la mano, como si hubiera creido que se estaba derrumbando el techo de mi casa. Pero después me volví a dormir, porque reconoci el sonido del río y porque ese sonido se fue haciendo igual hasta traerme otra vez el sueño"' (p. 31). Como siempre, Rulfo explota la ambigüedad de la palabra "sueño"' con su doble sentido de dormir y soñar.

Sueño que sigue por la mañana: el mismo estruendo de la noche, pero "más fuerte" y "más cerca" (p. 31); "agua revuelta" (p. 31).

"esa mujer que le dicen la Tambora" (p. 32): fórmula de resonancias sexuales (mala vida, embarazo) que la asocia con la Tacha. Comparar el "chapaleo" del agua que entra por el corral y sale "en grandes chorros" por la puerta de la Tambora (p. 32) con los "chorretes de agua sucia"' que llora Tacha "como si el río se hubiera metido dentro de ella" (p. 35). Otra resonancia: el "tambor" de la cabeza llena de fantasías sexuales de "Macario"' (p. 12). 
allá de las orillas de la carne". Pero se la lleva el mismo viento que la trajo: un soplo de caballo desbocado. Y ése es el mal "aliento" que anima al hijo: el aire de flauta, de caballos que vuelven, apocalípticos. Cabeceando los jinetes al trote silencioso de las "bestias" de sueño.

La "angustia" de Matilde, identificada con el hijo- esa "ansia" que le "entra" y le "crece", hasta que la muerte recuerda el parto-es material. Antes que la tierra que le llena la boca en la fosa la ataca el agua: el "charco lodoso" donde queda "sembrada".

$\mathrm{Y}$ también en "Es que somos muy pobres" el sueño emana del agua-elemento corruptor de la hermanita Tacha, materia sensible del dolor por la muerte de la tía Jacinta-como un efluvio de la conciencia.

El río-que es el sueño-crece, invade, arrastra. Llega retumbando de noche a llevarse al chico que despierta y salta un momento dentro del sueño y se abandona.

Sigue instalado el sueño por la mañana: agua revuelta, lluvia; ambiente y materia; mundo sumergido. Ya la Tambora-especie de sibila en el umbral del sueño-anunció el desborde. El río ha "perdido sus orillas"..${ }^{5}$ Ocupa las casas y los cuerpos; se hace cada vez más espeso y oscuro. La gente boquea como ahogada. La vaca Serpentina es una imagen del río que se la traga dormida. Soñando al borde del río, un leñador saca troncos con raíces del agua.

Al río iban las chicas a sacar agua; pero también a revolcarse con hombres. En los brazos del río violador se hicieron " pirujas". Por eso ahora la Tacha llora lágrimas de río: "chorretes de agua sucia como si el río se hubiera metido dentro de ella". También "de su boca sale un ruido semejante al que se arrastra por las orillas del río". El río que le hincha los pechos con su sabor a podrido-" "la creciente que sube" - es la imaginación de su desgracia, el sueño de su perdición.

En "Talpa": otra pesadilla de la materia. La "lumbre" de los cuerpos en el filo de la muerte. El fuego fatuo de una pasión culpable con gusto a tierra que pronto se vuelve polvo.

\footnotetext{
${ }^{5}$ El rio ha "perdido sus orillas" (p. 32); "aquel amontonadero de agua que cada vez se hace más espesa y oscura" (p. 32).

La gente que boquea como ahogada: " "abajo, junto al río, hay un gran ruidazal y sólo se ven las bocas de muchos que se abren y se cierran y como que quieren decir algo; pero no se oye nada" (p. 32).

La vaca Serpentina que cruza el río dormida, "con los ojos cerrados"' (p. 33). La imagen río-serpentina-sueño reaparece en "El hombre": "Muy abajo el río corre mullendo sus aguas entre sabinos florecidos; meciendo su espesa corriente en silencio. Camina y da vueltas sobre sí mismo.Va y viene como una serpentina enroscada sobre la tierra verde. No hace ruido. Uno podría dormir allí, junto a el, y alguien oiría la respiración de uno, pero no la del río" (p. 39).

El leñador que sueña al borde del río (p. 33); las "pirujas" y el río violador (p. 34); el río y la perdición de la Tacha (pp. 35-36).

La pesadilla de la materia: parece ser la tierra misma la que sueña. "Siempre sucedía que la tierra sobre la que dormíamos estaba caliente. Y la carne de Natalia, la esposa de mi hermano Tanilo, se calentaba en seguida con el calor de la tierra. Luego aquellos dos calores juntos quemaban y lo hacian a uno despertar de su sueño" (p. 58). ¿Despertar, más bien, dentro del sueño? En todo caso, dentro de la fiebrosa fantasía que da "lumbre" a los cuerpos (p. 58).

"a rastras...amarrados con hebras de polvo" (p. 59); las demás citas (pp. 59-60).
} 
Amantes y romeros, andan " a rastras", como "amarrados con hebras de polvo"'. E1 polvo, otro río, sube, bulle, los envuelve, los consume, bajo el cielo vacío. En su luz blanca de sueño se retuercen como "gusanos apelotonados"'. La vista se pierde, tropieza "contra algo que no se podía traspasar". Son vidas flotantes, sin otro rumbo que "cruzar el día". El cielo mismo es polvo, "como una mancha gris y pesada que nos aplastaba a todos desde arriba"'. El polvo de vidas en llamas también es "humo azul", ceniza de mortalidad. Si Rulfo lo compara con el "vapor que sale de la boca con el frío", es para decir: el soplo que escapa del cuerpo con la muerte. Dentro de ese soplo se hunden los culpables. Es el bulto vaporizado de su propio peso que les dobla el cuerpo. A Natalia se le borra la mirada "como si la hubiera revolcado en la tierra". En el mismo espejo opaco se ve morir Tanilo. ${ }^{6}$ Ahora el polvo es "un hervidero de moscas" que lo llenan " por dentro y por fuera" con un zumbido ronco de sueño: su propio estertor. Los amantes le echan tierra y piedras, lo fijan en la muerte. Pero ellos seguirán " de paso', comiendo el polvo del remordimiento: la culpa de estar vivos.

En "El hombre" vuelve el agua con su sueño de identidad. El que huye-de sí mismo-se busca en un cielo cada vez más lejano. Como siempre en Rulfo, es el cielo interior, la voz ontológica que llama. Por eso "el hombre" se oye en boca de otro. Al medirse contra el horizonte se desdobla. La sombra que lo persigue es su propio espectro. En el Voy a lo que voy suena el "vino por mí". Es el eco de su propia voz que dice: "Donde yo me detenga, allí estará".

En otro viaje, el de la venganza, hubo un desencuentro: llegó tarde a la cita con "la cara que él soñaba ver muerta"'. De ese momento "final"' arranca un tiempo sin límites: un eterno retorno. Es el tiempo del río que "camina y da vueltas sobre sí mismo". Cruzar el río sería estar a salvo, llegar al cielo donde no me conocen, donde nunca be estado y nadie sabe de mí. Pero el río atrapa en su "serpentina enroscada". Es la sustancia misma del que bebe su imagen del agua. En su respiración se oye la voz del otro que espera en el

\footnotetext{
6 Muerte y entierro de Tanilo (p. 65).
}

Los amantes "de paso" por el llano (y la vida): "Y yo comienzo a sentir como si hubiéramos llegado a ninguna parte; que estamos aquí de paso, para descansar, y que luego seguiremos caminando. No sé para dónde; pero tendremos que seguir, porque aqui estamos muy cerca del remordimiento y del recuerdo de Tanilo (p. 65).

"El hombre"' que se busca en un cielo cada vez más lejano: otra pequefra magia de!Rulfo , que lo muestra "deteniéndose en cada horizonte para medir su fin" y No el mí, sino el de él, es decir, el del otro que es él mismo (p. 37).

"El hombre", se oye en boca de otro: "Y volvió la cabeza para ver quién había hablado"' (p. 37); "Y supo que era él el que hablaba" (p. 37).

Voy a lo que voy (p. 37); "El vino por mí" (p. 41); "Y donde yo me detenga, allí estará" (p. 38).

La cita con "la cara que él soñaba ver muerta"' (p. 41); "era yo el final de su viaje"' (p. 41).

El río: "Camina y da vueltas sobre sí mismo. Va y viene como una serpentina enroscada sobre la tierra verde" (p. 39).

Tengo que estar al otro lado, donde no me conocen, donde nunca be estado y nadie sabe de mi (pp. 40-41).

Aqui el rio se bace un enredijo y puede devolverme a donde no quiero regresar (p. 41).

"Camino y camino y no ando nada..:Y mi tierra está lejos, más allá de aquellos cerros", (p. 45).

"boca abajo, con la cara metica en el agua" (p. 47); recordar la misma fórmula en "La herencia de Matilde Arcángel"' (p. 146). 
fondo. Cruzarlo, en todo caso, sería salir a la misma orilla, devuelto a donde no quiero regresar.

En las angosturas el rio se encajona; tira, misteriosamente, corriente arriba. Alejarse es perderse: "Camino y camino y no ando nada". Y siempre "mi tierra" sigue "lejos, más allá de aquellos cerros". Encontrarse, finalmente, es morir "boca abajo, con la cara metida en el agua".

Pero la tierra sigue llamando. Y más al que la mide con sus pasos sin darse cuenta que la va dejando atrás. Porque es la tierra pródiga, la patria soñada. Espejismo de paraíso en el desierto: el Llano Grande. Así lo sienten los paisanos de "Nos han dado la tierra", ", vagando "en medio de este camino sin orillas". Son cuatro que, de pronto, han caminado "más de lo que llevamos andado". Eran "veintitantos" que se han ido agotando como las horas del día. "Tanta y tamaña tierra para nada", se dicen, sin sospechar que en el momento de dejarla "allá arriba" volverá a ser la tierra prometida.

$\mathrm{Y}_{i}$ " "al otro lado"? Otra vez el pueblo: "Luvina", que "suena a nombre de cielo". Tierra empinada, loma de "piedra cruda"; en la punta, casi bíblico en su Calvario, el "blanco caserio", como "corona de muerto". El sueño, en este caso, es explícito. El hombre parado en la desolación de la "plaza sola" pregunta: "¿Qué pais es éste” y se contesta: "El purgatorio". Como todos, llegó con su ansia de cielo; pero lo esperaba el viento del abismo. En algún momento se dejó tragar por el aire negro: "arena de volcán". Lo trajo el arriero que en Rulfo reemplaza al botero de la muerte. Al inclinarse sobre el páramo interior sintió el viento en los huesos. Buscándose, vio figuras de enigma: caras entabladas, Parcas con cántaros al hombro, corporizaciones momentáneas de origenes perdidos, menos presentes que el "bulto" del viento en las calles. Con los años, "enrevesados" por "fiebres" de pesadilla, perdió la noción del tiempo, suspendido "como si se viviera siempre en la eternidad". También de las edades del hombre, detenidas en dos puntos: "los puros viejos y los que todavía no han nacido".

Al que cuenta lo carcomen los recuerdos: los muertos que le chupan la sangre. En el río chapotean los troncos del sueño. El horizonte, siempre lunar-en este caso gritos de niños, en vez de ladridos de perros-se aleja. El sol, como el viento, lo ha vaciado. La noche ${ }^{8}$ lo llena con "el silencio que hay en todas las soledades".

7 "Nos han dado la tierra" (pp. 15-20).

"Luvina" (pp. 94-104). Invasión del hombre por el viento volcánico de las barrancas de donde "suben los sueños" (p. 94). Viento cósmico que bulle "dentro de uno como si se pusiera a remover los goznes de nuestros mismos huesos" ( $p .95$ ). Son los mismos "goznes de la tierra" que "giran enmohecidos", rechinando como las poleas de la noria, a medida que el dia "va dándose vuelta"-la vida girando en su engranaje, el mundo en su eje gastado-en Pedro Páramo (pp. 113-114).

${ }^{8}$ El horizonte lunar: "Afuera seguia oyéndose cómo avanzaba la noche. El chapoteo del río contra los troncos de los camichines. El griterío ya muy lejano de los niños" (p. 104). El hombre que, "mirando un punto fijo", se recuesta sobre la mesa y se duerme (p. 104).

El " tiempo de la canicula" (p. 8): el punto muerto del año, meridiano del sueño. El sueño, en Rulfo, también es diurno. En el "sopor" de la canícula (p. 8), todo parece estar "como en espera de algo (p. 9). El estado anticipatorio recuerda el de "El llano en llamas", donde la acción arranca, o se despega, del "sueno del mediodía" (p. 67), con el "chirriar" de chicharras, un hombre "amodorrado por la siesta", otro "arrastrando su carabina como si fuera un leño" (p. 67). Pasan soldados "con el cuerpo echado para adelante, jorobados de sueño" (p. 68). Notable es el retrato del caudillo-sonador Pedro Zamora, con sus ojos "siempre desvelados" (p. 69); "ojos bien 
Así también llega Juan Preciado a Comala, en el "tiempo de la canícula", con "'los ojos reventados por el sopor del sueño"'. Del sueño surge el arriero sordo, su doble y hermano, que le sale al encuentro en un cruce de caminos. Del sueño también, la "laguna transparente"' de la llanura, hasta "la reverberación del sol". Porque, más que los influjos infernales, lo que da el ambiente, "de punta a cabo", a "toda la tierra que se puede abarcar con la mirada", es la Media Luna.

Y sabemos que la muerte-o la conciencia de la muerte-de Juan es lunar. " Al filo de la medianoche" se levanta la marea ontológica. Es el cuerpo de la madre-hermana que lo ahoga. Un cuerpo "hecho de tierra" - vientre y tumba-desbaratado en su propio sudor frío. Y, sorbiendo "el mismo aire que salia de mi boca" -el viento helado del vacío-, Juan se deja arrastrar.

LUIS HARSS

abiertos...que no dormian y que estaban acostumbrados a ver de noche", mientras sus hombres vagan "con los ojos aturdidos de sueño y con la idea ida", siguiéndolo "como si estuviéramos ciegos" (p. 79).

El arriero sordo, doble y hermano de Juan Preciado. Las alucinaciones acústicas, que se invierten (es Juan Preciado el que parece sordo), son parte del sueño. La sensación de imágenes superpuestas se da en un par de trazos: "Fui tras él tratando de emparejarme a su paso...Después los dos íbamos tan pegados que casi nos tocábamos los hombros"' (p. 9).

La "laguna transparente" en "la reverberación del sol" (p. 9). Notar el horizonte del sueño, vaporoso, gris, alejándose hasta "la más remota lejanía" (p. 9).

El influjo de la Media Luna (p. 10). Mismo influjo en "La Cuesta de las Comadres", cuando matan al arriero. Es "cuando alcanzamos el camino de la Media Luna" que empieza la oscuridad del sueño (p. 25).

Habría que hablar de las varias muertes de Juan: cuando empieza a "llenarme de sueños", al emprender el regreso a Comala (p. 7); en el momento del encuentro con su doble en un cruce de caminos (p. 9); en el cuarto del ahorcado, donde suelta sus "amarras" al sentirse "en un mundo lejano" (p. 15).

La muerte lunar, "al filo de la medianoche"" (p. 61). Acaba de entrar una Parca (pp. 57-58), identificada con la madre y con la hermana incestuosa (p. 60). El cuerpo "hecho de tierra" (p. 61), vientre y tumba (pp. 61 y 63).

Otra madre-tumba: Dorotea (p. 65). 